DOI: $10.17805 /$ zpu.2017.1.17

\title{
Возможности использования семантических информационных сервисов в музейном деле (на примере Музея истории ПетрГУ)*
}

\author{
С. Э. ЯЛОВИцЫНА
}

\author{
ИНСТИТУТ ЯЗЫКА, ЛИТЕРАТУРЫ И ИСТОРИИ КАРЕЛЬСКОГО НАУЧНОГО ЦЕНТРА \\ РОССИЙСКОЙ АКАДЕМИИ НАУК, ПЕТРОЗАВОДСКИЙ ГОСУДАРСТВЕННЫЙ УНИВЕРСИТЕТ, \\ В. В. ВОЛОХОВА, Д. Ж. КОРЗУН, А. Г. ВАРФОЛОМЕЕВ \\ ПЕТРОЗАВОДСКИЙ ГОСУДАРСТВЕННЫЙ УНИВЕРСИТЕТ
}

В статье представлен авторский подход к развитию Музея истории Петрозаводского государственного университета на основе такого вида цифровых услуг для посетителей и музейных работников, как семантические информационные сервисы. Мотивом к реализации семантических сервисов в деятельности музея стала необходимость контекстного поиска информации в музейном фонде, а также использования потенциала посетителей в пополнении фонда ранее не задействованной в экспозиции информацией и новыми экспонатами, в том числе в электронном виде.

Предложены сценарии использования сервисов, показывающие, какую информационную поддержку можно обеспечить в музее для: 1) отбора экспонатов для новых экспозиций, 2) персонализированного предоставления информации об экспонатах посетителю, 3) получения от посетителей музея новой информации о хранимых музейных экспонатах, 4) пополнения фонда музея за счет новых экспонатов в электронном виде, полученных от посетителей.

Основой предлагаемых сервисов является создаваемая в музее семантическая сеть, объединяющая как сами экспонаты музейного фонда, так и иные информационные объекты, связанные с конкретными экспонатами и историей университета и образования в целом. Особым вниманием при создании онтологии семантической сети пользуются у авторов информационные объекты, связанные с повседневной жизнью университетского сообщества.

Представленный подход может быть интересен не только музейным работникам, но и профессиональным исследователям, заинтересованным в получении и изучении новых фактов из истории повседневной жизни образовательно-научной организации.

Ключевые слова: музейная информационная система; музееведение; информационное обеспечение; семантические сервисы; история повседневности; Петрозаводский государственный университет; Музей истории Петрозаводского государственного университета

\section{BВЕАЕНИЕ}

М узей истории Петрозаводского государственного университета (ПетрГУ) был 1 воссоздан в 2015 г. в связи с празднованием 75-летнего юбилея вуза. К настоящему моменту общий объем фонда составляет около 10 тыс. единиц хранения. Стремление максимально эффективно использовать небольшое выставочное пространство

* Статья подготовлена при финансовой поддержке отделения гуманитарных и общественных наук РФФИ, проект № 16-01-12033 «Создание программной инфраструктуры для коллективного семантического аннотирования, связывания информации и персонализированного доступа к корпусу источников по истории повседневности».

This work is financially supported by Department for Humanities of Russian Foundation for Basic Research according to project № 16-01-12033 «Construction of Software Infrastructure for Collaborative Semantic Annotating, Information Linking, and Personalized Access to Corpus of Everyday life history Sources». 
(помещение площадью $47 \mathrm{M}^{2}$ ), с одной стороны, и повысить привлекательность музея для студентов и молодых преподавателей университета - многочисленной группы потенциальных посетителей - с другой, подтолкнули к активному применению медиааппаратуры. В результате в экспозиции сочетаются традиционные музейные витрины с вещественными экспонатами и серия экранов, на которых интерактивно отображается информация в цифровом виде.

Наряду с әкспозиционной работой было обращено внимание и на необходимость создания цифрового фонда экспонатов, который был реализован в форме учетной информационной системы (УИС). Такая система позволила объединить описание экспонатов и их образ (скан), осуществлять быстрый поиск әкспонатов по существующим в УИС полям или их сочетанию.

Новый формат экспозиции и наличие УИС подтолкнули авторов данной статьи к исследованию следующих прикладных задач, направленных на совершенствование работы музея и поддержку исторических исследований на его базе: совершенствование способов отбора экспонатов из музейного фонда для формирования новых экспозиций, включая тематические; повышение информационной отдачи музейных экспонатов за счет их семантической привязки к другим экспонатам, событиям, фактам и пр.; уточнение информации об экспонатах за счет сведений, поступающих от посетителей как от свидетелей и участников связанных с экспонатом событий; расширение фонда музея за счет новых экспонатов, представляемых посетителями в электронном виде; предоставление музейной информации посетителю в соответствии с его потенциальными интересами.

Аля создания информационного обеспечения, поддерживающего решение поставленных выше задач, предлагается использовать такой новый вид цифровых услуг, как семантические информационные сервисы (Korzun, 2016). Во-первых, информационный сервис является услугой по информационно-аналитической поддержке пользователя в процессе решения им прикладной задачи. В результате сервис должен находить и предоставлять пользователю подходящую для решения задачи информацию, например в виде рекомендаций по изучению того или иного исторического факта. Вовторых, семантический сервис подразумевает, что накопленная в музейном фонде информация представлена в виде семантической сети, где узлами выступают экспонаты и другие исторически значимые объекты (не обязательно представленные экспонатами), а связи между узлами описывают известные исторические отношения между такими объектами. В результате поиск сервисом информации сводится к анализу соответствующей семантической сети. Подобный подход характерен для приложений Семантического Веба (The Semantic Web) - новой парадигмы в развитии сети Интернет, основанной на таком представлении информации, при котором ее смысл становится понятным не только для человека, но и для компьютерных программ (Berners-Lee, Hendler, Lassila, 2001). Семантические сети являются удобным способом формального представления смысла информации, поэтому используются в качестве основы Семантического Веба. Таким образом, приходим к следующим технологическим задачам, связанным с созданием требуемого информационного обеспечения музея:

1) построение семантической сети для связывания информации музейного фонда на основе методов онтологического моделирования и технологий Семантического Веба;

2) персонализированный доступ посетителя к имеющейся информации музейного фонда на основе существующей УИС музея и с учетом индивидуальных интере- 
сов и особенностей человека при изучении им экспозиции (сервис «Учет профиля посетителя»);

3) вовлечение посетителей в процесс коллективного развития музейного фонда на основе добавления экспонатов (в электронном виде), их аннотирования и связывания с использованием информационно-коммуникационных технологий и разнообразной цифровой аппаратуры (сервисы «Аобавление атрибутов объекта», «Уточнение семантических связей», «Аобавление экспонатов в фонд музея»).

В данной статье рассматриваются возможные семантические информационные сервисы для поддержки решения посетителями и сотрудниками Музея истории ПетрГУ поставленных прикладных задач. Предложены сценарии использования таких сервисов. В итоге формируется новый подход к цифровому развитию музея, который позволяет помочь как профессиональным исследователям, так и другим людям получать и изучать новые факты из истории повседневной жизни образовательно-научной организации.

\section{УИС МУЗЕЯ ИСТОРИИ ПЕТРГУ: \\ ОБЩАЯ ХАРАКТЕРИСТИКА}

Аля ведения учета экспонатов музейного фонда в Музее истории ПетрГУ разработана и внедрена специализированная УИС. Карточка экспоната в УИС позволяет описать экспонат в соответствии с традиционными музейными требованиями. Состав полей соответствует музейным ведомственным программным средствам, например таким, как «КАМИС-музейные системы» (http://www.kamis.ru). Соответственно, УИС может считаться типовым вариантом информатизации музейного фонда, при котором на первый план выдвигается задача учета экспонатов.

Использование электронной учетной системы, безусловно, облегчило задачу поиска экспонатов по содержанию имеющихся в УИС полей. Однако некоторые экспонаты, контекстно связанные с поисковым запросом, «ускользали» из выборки прежде всего по причине отсутствия прямого указания (в виде конкретного слова) в поисковом поле (полях). Частой бывает ситуация, когда гость музея приблизительно помнит о некой конференции, в которой он когда-то участвовал в стенах университета, и просит найти экспонаты (фотографии, программы), свидетельствующие о его участии в ней. Это не всегда оказывается возможным, если фамилия гостя не зафиксирована в полях УИС. В такой ситуации было бы весьма полезно иметь возможность извлекать информацию по другим словам и (или) связанными с ними контекстам, выстраиваемым автоматически. Такой же сервис может быть необходим при любых других косвенных поисках.

Более того, внимание к запросу посетителя в последнее время является мировым трендом музейного дела. Сегодня популярным классом музейных информационных систем становятся сервисы для посетителей. Например, пользователи системы SMARTMUSEUM получают рекомендации от системы, формируемые с учетом сведений об их местоположении и интересах (SMARTMUSEUM ..., 2013: Электронный ресурс). Наряду с рекомендациями построения индивидуального маршрута экскурсии, современные информационные системы способны поддерживать обратную связь с посетителями музея (An integrative framework ... , 2015). Новые информационнокоммуникационные технологии и разнообразная цифровая аппаратура открывают дополнительные способы взаимодействия посетителей с информацией музейного фонда во время изучения экспозиции (Smirnov, Shilov, Kashevnik, 2012). 
Знакомство с опытом использования новых сервисов (так называемых умных сервисов), предлагаемых современными музеями, а также имеющийся в музее истории ПетрГУ задел, связанный с УИС, подтолкнули к созданию и развертыванию на цифровой аппаратуре музея программной инфраструктуры, расширяющей возможности УИС за счет построения и доставки пользователям так называемых семантических информационных сервисов (СИС).

На данный момент УИС используется для учета экспонатов и их поиска по формальным полям. Большой объем фонда заставляет искать более эффективные пути отбора и систематизации информации. В частности, при формировании экспозиций возникает необходимость выявления экспонатов музейного фонда, связанных между собой. В качестве примера можно привести подготовку биографической выставки о ректорах университета. Воспользовавшись стандартной процедурой поиска, можно обнаружить в УИС те экспонаты, в описании которых прямо указан кто-либо из бывших ректоров. Однако опосредованные, скрытые связи не будут видны.

К примеру, занимавший пост ректора университета в 1941-1944 гг. К. А. Митропольский (1893-1983 гг.) логически связан практически со всеми статьями об университете, опубликованными в газете «За новый Север» в период эвакуации вуза в Сыктывкар (1942-1944 гг.), так как он возглавлял университет в годы войны. Но фамилия Митропольского не всегда упоминается в этих материалах. Обнаружить связь экспонатов с биографией Митропольского возможно с помощью семантического сервиса. Обеспечивать работу такого сервиса должна семантическая сеть.

Под семантической сетью понимается информационная модель, которая описывает объекты, явления и понятия предметной области с помощью сетевых структур, основанных на теории графов (Оре, 1980). В названии соединены термины из двух наук: семантика в языкознании изучает смысл единиц языка, а сеть в математике представляет собой разновидность ориентированного графа - набора узлов и набора дуг, попарно соединяющих узлы. Узлы семантической сети соответствуют объектам, а дуги - отношениям между объектами. С дугами могут быть ассоциированы атрибуты для описания содержательной смысловой нагрузки в виде семантических связей между объектами.

В случае музея объектами предметной области являются как экспонаты, так и другие исторически значимые сущности: персоналии, географические точки, события и др. Семантические связи между объектами могут быть самыми разными. Самый простой вид связи может быть представлен как «упоминается в...». Так, Петрозаводский университет упоминается в статьях газеты «За новый Север». Более сложный вид связи - указание одного объекта как части другого. Например, дата создания объявления в газете «За новый Север» - 25 февраля 1944 г. - является частью хронологического периода - 1941-1944 гг. - времени, когда университет находился в эвакуации в Сыктывкаре. Именно благодаря тому, что К. А. Митропольский также связан с этим хронологическим отрезком, так как возглавлял университет в годы эвакуации, и возникает опосредованная связь между ним и статьей в газете «За новый Север», в которой он лично не упоминается.

Использование информационных сервисов, опирающихся на семантическую сеть, открывает перед сотрудниками музея возможности, отсутствующие у УИС. Это не только более сложный поиск экспонатов для будущей выставки, но и получение новых сведений об истории университета на основе уже имеющихся экспонатов. Так, достраивание семантической сети, описанной выше, позволило увидеть связь между К. А. Митропольским и Н. Н. Ростовцевым, преподававшим в университете в период 
эвакуации в Сыктывкар и защитившим там диссертацию, о чем было помещено объявление все в той же газете «За новый Север». Значимость данного факта должна быть установлена уже исследователем, но попасть в его поле зрения он может именно благодаря семантическому сервису, устанавливающему связи между объектами.

Особенно полезным построение семантических сетей может быть при использовании экспонатов музея в изучении истории повседневности, которая вызывает повышенный интерес у посетителей. Поиск сведений по этой тематике непосредственно в УИС затруднен тем, что в его основе лежат структуры, как правило, не используемые при описании: питание, обстановка в комнате общежития, одежда и т. п. На наш взгляд, создание семантических информационных сервисов позволит осуществлять быстрое выявление и систематизацию экспонатов по данной тематике для экспозиции музея, покажет взаимосвязь отдельных событий и явлений, обратит внимание на малоизученные стороны повседневного быта университета.

\section{СЕМАНТИЧЕСКИЙ СЕРВИС «УЧЕТ ПРОФИАЯ ПОСЕТИТЕАЯ»}

Сама по себе идея использования рекомендательных сервисов для предоставления посетителю в пространстве музея не нова. Интерактивные технологии все более широко применяются в музейных экспозициях. В большинстве случае речь идет о реализации для посетителя возможности самому делать запрос на поиск интересующей его информации и выбирать уровень ее предъявления в ходе осмотра экспозиции (Ванеева, 2015; Труевцева, 2014). Уже имеется ряд примеров построения системы «Умный музей» (SMARTMUSEUM system), главной функцией которой является построение маршрута осмотра экспозиции на основе профиля посетителя (Chianese, Piccialli, 2014; Cui, Yokoi, 2012). В условиях небольшого экспозиционного пространства музея истории ПетрГУ и использования выставок как визитной карточки вуза в рамках самых разных мероприятий с участием различной аудитории применение подобных технологий является залогом успешного существования музея.

В связи с этим были рассмотрены возможности автоматического формирования гибкой, подстраиваемой под профиль посетителя, виртуальной экспозиции. Например, семантическая сеть может быть востребована в ситуации, когда в музей пришла группа гостей из другой страны. Предварительное, перед началом экскурсии, создание профиля посетителя позволит информационной системе найти экспонаты, так или иначе связанные с участием университета в международном сотрудничестве, с акцентом на страну гостей. Так, например, преподавателю университета, прибывшему из Франции, семантический сервис «Учет профиля посетителя» предложит познакомиться с экспонатами, опосредованно связанными с университетами Франции. Могут быть также учтены возрастные, гендерные, профессиональные и другие характеристики посетителя.

\section{СЕМАНТИЧЕСКИЕ СЕРВИСЫ «АОБАВАЕНИЕ АТРИБУТОВ ОБЪЕКТА " И «УТОЧНЕНИЕ СЕМАНТИЧЕСКИХ СВЯЗЕЙ»}

Сегодня использование информационных технологий в музеях направлено прежде всего на расширение информации об экспонатах, предоставляемой пользователю, в том числе за счет ресурсов Интернета. Возможности Всемирной сети позволяют посетителям музея узнать об экспонатах многое и без посещения музея, а также дополнить информацию о музейной экспозиции собственными данными, не презентуемыми в этикетаже и иной сопровождающей информации. 
Виртуальные экспозиции, широко представленные в музее истории ПетрГУ, дают возможности более активного взаимодействия пользователя и музея. Здесь необходимо учитывать и особенности аудитории музея истории ПетрГУ: как правило, это люди, связанные с настоящим или прошлым вуза, а следовательно, располагающие определенным объемом информации об его истории. Они могли бы существенно обогатить фонды сведениями об имеющихся экспонатах. При этом важно не упустить эту информацию, записать ее «здесь и сейчас». К примеру, типичной является ситуация, когда на групповом снимке идентифицируются на этикетке выставочного экрана лишь главные герои, в то время как остальные остаются безвестными.

Семантический сервис «Аобавление атрибутов объекта», действующий на основе нижеприведенного сценария, позволит посетителю сообщить сотрудниками музея имеющиеся у него сведения.

Сиенарий дополнения посетителем недостающей информачии об объекте сематической сети:

- посетитель музея видит какой-либо экспонат в экспозиции и хочет добавить информацию о нем;

- посетитель знакомится с условиями и полномочиями о дополнении информации;

- посетитель имеет возможность увидеть описание экспоната в трех вариантах:

1) как подпись к экспонату (этикетка);

2) как учетную карточку экспоната (из УИС);

3) как совокупность связей объекта семантической сети (выбор визуализируемых связей зависит от профиля посетителя, составляемого в момент входа в систему);

- посетитель может что-то добавить к описанию следующими способами (вся дополненная информация сохраняется в дополнительном хранилище данных с сохранением связи с редактируемым объектом):

1) записать аудио (видео) с комментариями к объекту;

2) составить текстовый комментарий к объекту.

Сведения посетителей также могут касаться не конкретных объектов семантической сети, а связей между объектами. Например, в музее хранится переписка одного из первых преподавателей, выехавших на длительную стажировку за рубеж, однако другой участник переписки нам не известен. Посетители музея верно подсказали нам второго корреспондента, что во многом объяснило характер писем.

Сиенарий выявления посетителем связей между объектами семантической сетu:

- посетитель активирует опцию «имеющиеся связи» исходного объекта (например, письмо) и знакомится с ними;

- посетитель находит в системе с помощью поискового запроса новый объект семантической сети, с которым, по его мнению, может быть связан исходный объект (например, адресат письма);

- информационная система строит совокупность связей между заданными объектами или констатирует отсутствие связи.

Очевидно, что дополненная посетителем информация нуждается в экспертизе, которую осуществляет сотрудник музея. В результате проверки он переносит новые сведения в УИС, хотя исходные данные также могут быть сохранены.

Построение семантической сети позволит не только механически пополнять УИС новыми данными (после соответствующей экспертизы), но и встраивать появившуюся 
информацию в уже имеющийся комплекс сведений по той или иной тематике. Семантические сервисы могут подсказывать посетителю, решившему уточнить какие-то сведения экспозиции, новые объекты, связанные с заинтересовавшим его экспонатом. Например, узнав одного из ранее неизвестных персонажей на одном из представляемых фотоснимков, посетитель или позже работник музея может найти его и на других фото той же тематики.

\section{СЕМАНТИЧЕСКИЙ СЕРВИС «АОБАВАЕНИЕ НОВЫХ ЭКСПОНАТОВ В ФОНА МУЗЕЯ»}

Взаимодействие музея и его посетителей не может ограничиться уточнением сведений об экспонатах и объектах семантической сети. Аля восстановления истории повседневности посетители сами являются богатым источником исторических сведений, будучи участниками или свидетелями соответствующих событий.

ПетрГУ был основан в 1940 г. Хронологически его история не выходит за пределы временного периода, для которого Я. Ассман использовал термин «коммуникативная память». По мнению немецкого историка, коммуникативная память охватывает то содержание памяти, которое основано на ежедневной коммуникации внутри социальной группы (Ассман, 2004: 58-59). Советское прошлое сегодня находится в центре повседневного обсуждения, память о нем формируется под воздействием самых разных факторов и является еще частью опыта большинства россиян. И для посетителей музея ПетрГУ обращение к истории вуза - это, по сути, обращение к истории советской повседневности, содержащее определенное осмысление и оценивание пережитого прошлого в тесной связи с настоящим.

Самый распространенный экспонат экспозиций музея истории ПетрГУ - это фотографии - источник, который как нельзя лучше позволяет провоцировать воспоминания, диалог о прошлом. Фотография часто становится толчком для рассказа. Музейная экспозиция с ее визуальным и предметным рядом вызывает воспоминания о тех деталях повседневности, которые, будучи частью обыденности, не всегда в интервью описываются информантами. Более того, фотография способна стать опорной точкой для воспоминаний, провоцируя рассказ о том, что не изображено на фотографии непосредственно. Посетитель, узнав на фотографии персонажа, чье имя не было указано на этикетке, порой тут же начинает делиться воспоминаниями об этом человеке, сообщая сведения, не относящиеся к моменту съемки. Чрезвычайно важно зафиксировать рассказ посетителя, создавая, по сути новый, теперь уже аудио, источник. И чем әффективнее семантические сервисы будут предлагать посетителю новые объекты, связанные с заинтересовавшим его экспонатом, тем интереснее и информативнее будет записанная в музее «устная история».

Однако сама по себе фотография, как отметил А. Секула, представляет лишь возможность значения, и эта возможность реализуется в конкретной ситуации (Sekula, 1982: 91). Например, в то время как бывший студент ПетрГУ видит в фотографии 1960-х годов момент занятия в лаборатории, современные студенты в первую очередь указывают на необычное для них оборудование, а также прически и одежду, которые для них становятся приметами другого времени. Исследователи советской фотографии О. Саркисова и О. Шевченко отмечают: «...фотографии не просто оказываются кладезями личных воспоминаний, но становятся источником и доказательством обоснования определенного взгляда на прошлое. <..> Комментарии к фотографиям... позволяют выявить большое разнообразие идеологических позиций, сторонники ко- 
торых редко готовы к открытому и аргументированному диалогу друг с другом» (Саркисова, Шевченко, 2015: Электронный ресурс).

Так, в результате «разглядывания» фотографии в Музее истории ПетрГУ и реализации семантического сервиса «Аобавление нового экспоната» может появиться целый ряд новых экспонатов - аудиоинтервью об отдельных событиях, личностях, связанных с уже имеющимися экспонатами, а также отражающих восприятие информации этих экспонатов современными зрителями.

\section{ЗАКАЮЧЕНИЕ}

В статье рассмотрены возможные семантические информационные сервисы, на основе которых предлагается выполнить цифровое развитие Музея истории ПетрГУ. Такими сервисами выступают «Учет профиля посетителя», «Аобавление атрибутов объекта», «Уточнение семантических связей», «Аобавление экспонатов в фонд музея». В результате, обеспечивается новый вид информационной поддержки работы музея при решении следующих прикладных задач: 1) отбор экспонатов для новых экспозиций, 2) персонализированное предоставление посетителю информации об экспонатах и объектах семантической сети, 3) получение от посетителей музея новой информации о хранимых экспонатах, 4) пополнение фонда музея за счет новых экспонатов в электронном виде от посетителей. Аля этих сервисов предложены и разобраны на примерах сценарии использования.

В целом сформирован авторский подход к построению информационной поддержки, позволяющей как профессиональным исследователям, так и другим заинтересованным людям получать и изучать новые факты из истории повседневной жизни образовательно-научной организации. Внедрение сервисов будет способствовать повышению привлекательности музея для посетителей, сделает экспозиции более мобильными, повысит информационную отдачу накопленного материала, позволит расширить источниковую базу музейного фонда. Применение этого подхода возможно не только для развития рассмотренного музея. Круг поддерживаемых прикладных задач не ограничен музейной экспозиционной деятельностью, но может быть применен и в практике исследовательской деятельности историков.

\section{СПИСОК АИТЕРАТУРЫ}

Ассман, Я. (2004) Культурная память: Письмо и память о прошлом и политическая идентичность в высоких культурах древности / пер. с нем. М. М. Сокольской. М. : Языки славянской культуры. 368 с.

Ванеева, О. В. (2015) Комплексное использование интерактивных технологий в рамках музейного пространства // Труды Санкт-Петербургского государственного института культуры. T. 212. C. 189-169.

Ope, О. (1980) Теория графов. М. : Наука. 336 с.

Саркисова, О., Шевченко, О. (2015) В поисках советского прошлого: Аюбительская фотография и семейная память [Электронный ресурс] // Новое литературное обозрение. № 1. URL: http://magazines.russ.ru/nlo/2015/1/9s.html (дата обращения: 15.06.2016).

Труевцева, О. Н. (2014) Индивидуальная работа с музейным посетителем// Вестник Алтайской науки. № 2-3. С. 156-160.

Berners-Lee, T., Hendler, J., Lassila, O. (2001) The Semantic Web // Scientific American. №5. P. 34-43.

Chianese, A., Piccialli, F. (2014) Designing a smart museum: When cultural heritage joins IoT // 2014 Eighth International Conference on Next Generation Mobile Apps, Services and Technologies (NGMAST 2014). P. 300-306. 
Cui, B., Yokoi, S. (2012) Promote visitor interactions by smart devices in museum learning scenario // 2012 8th International Conference on Computing Technology and Information Management (NCM 2012 and ICNIT 2012). Vol. 1. P. 376-379.

Korzun, D. (2016) On the smart spaces approach to semantic-driven design of service-oriented information systems [Электронный ресурс]// Communications in Computer and Information Science. Vol. 615. Springer International Publishing, June. P. 181-195. DOI: 10.1007/978-3-319-40180-5_13

An integrative framework for extending the boundaries of the museum visit experience: linking the pre, during and post visit phases (2015) / Kuflik, T., Wecker, A., Lanir, J., Stock, O. // Information Technology \& Tourism. № 15(1). P. 17-47. DOI: 10.1007/s40558-014-0018-4

SMARTMUSEUM: A mobile recommender system for the Web of Data (2013) / Ruotsalo, T., Haav, K., Stoyanov, A., Roche, S., Fani, E., Deliai, R., Makela, E.,Kauppinen, T., Hyvonen, E. [Электронный ресурс]// Web Semantics: Science, Services and Agents on the World Wide Web. Vol. 20. P. 50-67. URL: http://www.websemanticsjournal.org/index.php/ps/article/view/330 (дата обращения: 12.08.2016).

Sekula, A. (1982) On the Invention of Photographic Meaning // Thinking Photography / Ed. V. Burgin. London : Macmillan. 239 p. P. 84-109.

Smirnov, A., Shilov N., Kashevnik A. (2012) Ontology-based Mobile Smart Museums Service // AFIN 2012. The Fourth International Conference on Advances in Future Internet / Ed. by A. Bogliolo, P. Lorenz. Curran Associates, Inc. P. 48-54.

Аата поступления: 30.10.2016 г.

DIGITAL DEVELOPMENT OF THE MUSEUM

OF THE HISTORY OF PETROZAVODSK STATE UNIVERSITY THROUGH SEMANTIC

INFORMATION SERVICES

S. E. YALOVITSYNA

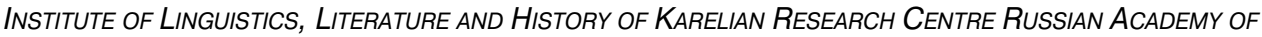
Sciences, Petrozavodsk State University

V. V. Volokhova, D. Zh. Korzun, A. G. Varfolomeyev

PetRozavodsK State UNIVERSITY

The article presents the author's approach to the development of the Museum of the History of Petrozavodsk State University based on digital services for visitors and museum staff, such as semantic information services. The reason for implementing semantic services in the museum's work was the need for contextual search in the museum's fund, as well as utilizing visitors' contribution to replenishment of the fund with information that was not used before and with new exhibits, including those in the electronic format.

In this work we propose scenarios for utilizing services that show what kind of information support can be provided at the museum for: 1) selecting exhibits for new exhibitions, 2) personalized delivery of information to the visitor, 3) receiving new information on items stored in the museum's from visitors, 4) replenishment of the museum's fund with new exhibits in the electronic format, donated by visitors.

The platform for suggested services is a semantic network currently being created at the museum, which unites the items of the museum's fund and other information objects connected with certain exhibits and the history of the university and education in general. When they were creating the ontology of the semantic network, the authors' special attention was attracted by the information objects connected to the everyday life of the university community.

The presented approach can be interesting not only to the museum staff, but also to professional researchers interested in receiving and studying new facts from the history of everyday life of the educational and research institution.

Keywords: museum information system; museology; information support; semantic services; history of everyday life; Museum of the History of Petrozavodsk State University; Petrozavodsk State University 
REFERENCES

Assman, Ia. (2004) Kul'turnaia pamiat' : Pis'mo i pamiat' o proshlom i politicheskaia identichnost' v vysokikb kul'turakb drevnosti, transl. by Germ. Moscow, Iazyki slavianskoi kul'tury. 368 p. (In Russ.).

Vaneeva, O. V. (2015) Kompleksnoe ispol'zovanie interaktivnykh tekhnologii v ramkakh muzeinogo prostranstva. Trudy Sankt-Peterburgskogo gosudarstvennogo instituta kul'tury, vol. 212, pp. 189-169. (In Russ.).

Ore, O. (1980) Teoriia grafov. Moscow, Nauka. 336 p. (In Russ.).

Sarkisova, O. and Shevchenko, O. (2015) V poiskakh sovetskogo proshlogo: Liubitel'skaia fotografiia i semeinaia pamiat'. Novoe literaturnoe obozrenie, no. 1 [online] Available at: http://magazines.russ.ru/nlo/2015/1/9s.html (access data : 15.06.2016). (In Russ.).

Truevtseva, O. N. (2014) Individual'naia rabota s muzeinym posetitelem. Vestnik Altaiskoi nauki, no. 2-3, pp. 156-160. (In Russ.).

Berners-Lee, T., Hendler, J. and Lassila, O. (2001) The Semantic Web. Scientific American, no. 5, pp. 34-43.

Chianese, A. and Piccialli, F. (2014) Designing a smart museum: When cultural heritage joins IoT. In: 2014 Eighth International Conference on Next Generation Mobile Apps, Services and Technologies (NGMAST 2014). P. 300-306.

Cui, B. and Yokoi, S. (2012) Promote visitor interactions by smart devices in museum learning scenario. In: 2012 8th International Conference on Computing Technology and Information Management (NCM 2012 and ICNIT 2012), vol. 1, pp. 376-379.

Korzun, D. (2016) On the smart spaces approach to semantic-driven design of service-oriented information systems. Communications in Computer and Information Science, vol. 615. Springer International Publishing, June. P. 181-195. DOI: 10.1007/978-3-319-40180-5_13

An integrative framework for extending the boundaries of the museum visit experience: linking the pre, during and post visit phases (2015) / Kuflik, T., Wecker, A., Lanir, J. and Stock, O. Information Technology \& Tourism, no. 15(1), pp. 17-47. DOI: 10.1007/s40558-014-0018-4

SMARTMUSEUM: A mobile recommender system for the Web of Data (2013)/ Ruotsalo, T., Haav, K., Stoyanov, A., Roche, S., Fani, E., Deliai, R., Makela, E.,Kauppinen, T. and Hyvonen, E. Web Semantics: Science, Services and Agents on the World Wide Web, vol. 20, pp. 50-67 [online] Available at: http://www.websemanticsjournal.org/index.php/ps/article/view/330 (access data: 12.08.2016).

Sekula, A. (1982) On the Invention of Photographic Meaning. In: Thinking Photography, ed. V. Burgin. London, Macmillan. 239 p. Pp. 84-109.

Smirnov, A., Shilov N. and Kashevnik A. (2012) Ontology-based Mobile Smart Museums Service. In: AFIN 2012. The Fourth International Conference on Advances in Future Internet, ed. by A. Bogliolo and P. Lorenz. Curran Associates, Inc. P. 48-54.

Submission date: 30.10.2016.

Яловицына Светлана Эрккиевна - кандидат исторических наук, и. о. заместителя директора по науке Института языка, литературы и истории Карельского научного центра Российской академии наук, директор Музея истории Петрозаводского государственного университета, доцент кафедры отечественной истории Института истории, политических и социальных наук Петрозаводского государственного университета. Адрес: 185910, Россия, г. Петрозаводск, ул. Пушкинская, д. 11. Тел.: +7 (8142) 78-44-96. Эл. адрес: jalov@yandex.ru

Волохова Валентина Владимировна - кандидат исторических наук, доцент кафедры отечественной истории Института истории, политических и социальных наук Петрозаводского государственного университета. Адрес: 185910, Россия, г. Петрозаводск, пр. Аенина, А. 33. Тел.: (814-2) 71-96-49. Эл. алрес: vavolokhova@yandex.ru

Корзун Амитрий Жоржевич - кандидат физико-математических наук, доцент кафедры информатики и математического обеспечения Института математики и информационных техно- 
логий Петрозаводского государственного университета. Адрес: 185910, Россия, г. Петрозаводск, просп. Аенина, д. 33. Тел.: (814-2) 71-10-84. Эл. адрес: dkorzun@cs.karelia.ru

Варфоломеев Алексей Геннадьевич - кандидат физико-математических наук, доцент кафедры теории вероятностей и анализа данных Института математики и информационных технологий Петрозаводского государственного университета. Адрес: 185910, Россия, г. Петрозаводск, просп. Иенина, А. 33. Тел.: (814-2) 71-10-78. Эл. адрес: avarf@petrsu.ru

Yalovitsyna Svetlana Erkkievna, Candidate of History, Institute of Linguistics, Literature and History, Karelian Research Centre, Russian Academy of Sciences; Director of the Museum of History of Petrozavodsk State University; Associate Professor, Department of Russian History, Institute of History, Political and Social Sciences, Petrozavodsk State University. Postal address: 11 Pushkin st., Petrozavodsk, Russian Federation, 185910. Tel.: +7 (8142) 78-44-96. E-mail: jalov@yandex.ru

Volokhova Valentina Vladimirovna, Candidate of History, Associate Professor, Department of Russian History, Institute of History, Political and Social Sciences, Petrozavodsk State University. Postal address: 33 Lenin Ave., Petrozavodsk, Russian Federation, 185910. Tel.: + 7 (8142) 71-96-49. E-mail: vavolokhova@yandex.ru

Korzun Dmitry Zhorzhevich, Candidate of Physico-Mathematical Sciences, Associate Professor, Department of Computer Science, Institute of Mathematics and Information Technology, Petrozavodsk State University. Postal address: 33 Lenin Ave., Petrozavodsk, Russian Federation, 185910. Tel.: +7 (814-2) 71-10-84. E-mail: dkorzun@cs.karelia.ru

Varfolomeyev Aleksey Gennad'evich, Candidate of Physico-Mathematical Sciences, Associate Professor, Department of Probability Theory and Data Analysis, Institute of Mathematics and Information Technology, Petrozavodsk State University. Postal address: 33 Lenin Ave., Petrozavodsk, Russian Federation, 185910. Tel.: +7 (814-2) 71-10-78. E-mail: avarf@petrsu.ru 